\title{
Fatal holocord recurrence of a pregnancy-related, low-grade spinal ependymoma: case report and review of an unusual clinical phenomenon
}

\author{
Sumit Thakar ${ }^{1} \cdot$ Laxminadh Sivaraju $^{1} \cdot$ Nandita Ghosal $^{2} \cdot$ Saritha Aryan $^{1} \cdot$ Alangar S. Hegde $^{1}$
}

Received: 24 August 2020 / Revised: 8 September 2020 / Accepted: 9 September 2020

(c) International Spinal Cord Society 2020

\begin{abstract}
Introduction Pregnancy-related spinal tumors (PRSTs) are unusual tumors that present during pregnancy or within a year after delivery. We describe a fatal holocord recurrence of a spinal ependymoma, which, to the best of our knowledge, is one of the most extensive PRSTs reported thus far.

Case presentation A 21-year-old primigravida presented at 6 months of gestation with urinary incontinence for 2 months and spastic paraparesis for 1 month. MRI showed a conus intramedullary lesion from T10 to 12 . Near-total resection of the lesion was performed. The histopathological diagnosis was that of a cellular ependymoma (WHO grade II). The patient presented 6 months later with progressive quadriparesis and breathing difficulty. MRI demonstrated holocord recurrence of the tumor with edema extending to the pontomedullary junction. The patient succumbed to respiratory failure before decompression of the tumor could be performed.

Discussion This case highlights an unusual clinical course of a pregnancy-related, low-grade spinal ependymoma. The possible hormonal and genetic mechanisms underlying the aggressive involvement of the entire spinal cord by the recurrent tumor are discussed in the light of a literature review. Future studies may shed light on the possibility of utilizing these mechanisms as therapeutic targets to alter the clinical course of aggressive spinal ependymomas.
\end{abstract}

\section{Introduction}

Holocord intramedullary tumors form a rare subset of primary spinal cord tumors that extend from the cervicomedullary junction to the conus medullaris, spanning close to 20 contiguous cord segments [1]. A majority of these "panspinal" tumors are pilocytic or diffuse astrocytomas $[1,2]$. The occurrence of a holocord ependymoma is anecdotal, with $<10$ cases reported (Table 1) [3-9] after Cushing's first report of the entity [10]. We describe the first case of a holocord "recurrence" of a low-grade spinal ependymoma. The tumor first presented during pregnancy and had

Sumit Thakar

sumit.thakar@gmail.com

1 Department of Neurosurgery, Sri Sathya Sai Institute of Higher Medical Sciences, EPIP Area, Whitefield, Bangalore, Karnataka 560066, India

2 Department of Pathology, Sri Sathya Sai Institute of Higher Medical Sciences, EPIP Area, Whitefield, Bangalore, Karnataka 560066, India an early recurrence, which, to the best of our knowledge, is the one of the most aggressive pregnancy-related spinal tumors (PRSTs) reported in literature. The tumorogenic mechanisms of pregnancy, their effects on the clinical course of spinal tumors, and possible underlying genetic alterations that contribute to aggressiveness of spinal ependymomas are discussed in the light of a literature review.

\section{Case presentation}

A 21-year-old primigravida from a rural background presented at 6 months of gestation with urinary incontinence for 2 months and progressive tightness and weakness of both her lower limbs for 1 month. Neurological examination revealed severe spasticity of both lower limbs that precluded assessment of power. Deep tendon reflexes were brisk and the plantar reflex was bilaterally upgoing. The rest of her neurological examination was normal. MRI of her spine (Fig. 1) showed an intramedullary lesion in the region of the conus extending from T10 to 12 vertebral levels. The lesion was isointense on T1-weighted images (WI) and 
hyperintense on T2 WI. It had a ventrally exophytic component. Screening of the rest of the spine was normal. Gadolinium was not administered as a precautionary measure in view of her pregnancy. Ultrasound of the pelvis confirmed a single live intrauterine fetus with an estimated gestational age of 28 weeks.

She underwent T10-T12 laminectomy and resection of the tumor in the left lateral position with somatosensoryevoked potential and motor-evoked potential monitoring under general anesthesia with due precautions for maternal and fetal safety. Intraoperatively, a firm, grayish, and moderately vascular intramedullary tumor was encountered. Near-total resection was achieved, with a thin residue left behind at the conus where the tumor-cord interface was relatively poor.

Histopathological examination revealed a cellular tumor (Fig. 2) with round to oval cells arranged in a fibrillary matrix. The cells had strong and diffuse glial fibrillary acidic protein positivity and focal positivity for epithelial membrane antigen, and demonstrated a MIB-1 labeling index of $10-12 \%$. There was evidence of attempted ependymal rosette formation. No mitosis, necrosis, or microvascular proliferation was seen. These features were consistent with a diagnosis of a cellular ependymoma (WHO Grade II).

Following surgery, the patient underwent physiotherapy with an individualized rehabilitation program tailored toward achieving functional independence. Some of the specific neuromuscular facilitation exercises included sustained stretching of the hamstrings, quadriceps and calf muscles, passive force rocking movements of the lower limbs, and body-weight supported weight-bearing and tilttable standing activities to reduce spasticity. She was also provided occupational therapy training in newborn care strategies for safe feeding and carrying the child.

At the time of discharge, there was some improvement in spasticity in her lower limbs, and the power had improved to grade 3 at the hip and knee on the left and grade 2 at the hip and knee on the right. She was advised to continue clean intermittent catheterization and was prescribed long knee callipers to aid walking. The caretakers were educated on continuing physiotherapy at home with advice on prevention of decubitus-related complications.

The patient was advised to follow-up after completion of her pregnancy, and the obstetrician was updated about her condition. Following her discharge from hospital, she diligently continued physiotherapy at home, and continued to experience further improvement in her lower limb and bladder function. Three months after an uneventful full-term delivery, she presented in the emergency department with worsening spasticity in the lower limbs for a month, paresthesias and tightness in the upper limbs for 1 week, and difficulty in breathing for a day. On examination, she was noted to have spastic quadriparesis with brisk tendon 

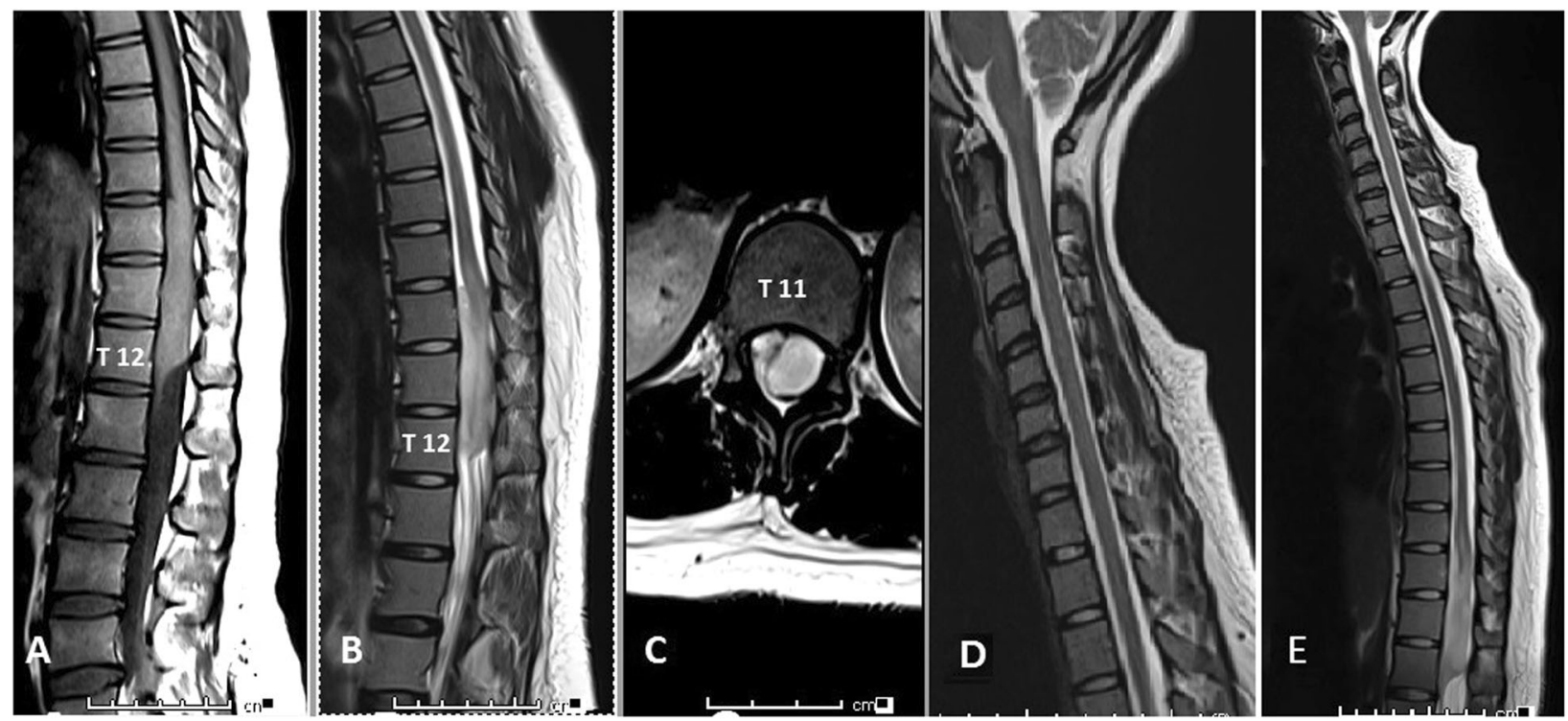

Fig. 1 Plain MRI of the spine showing an intramedullary lesion in the region of the conus. a Sagittal $\mathrm{T} 1$-weighted image showing an isointense lesion extending from T10 to T12, b Sagittal T2-weighted image demonstrating the lesion to be hyperintense. A ventrally exophytic component is noted. c T2-weighted axial sequence at T11 level showing an enlarged cord and the exophytic component. d Screening T2-weighted image of the cervical spine and e wholespine screening showing no other lesion.

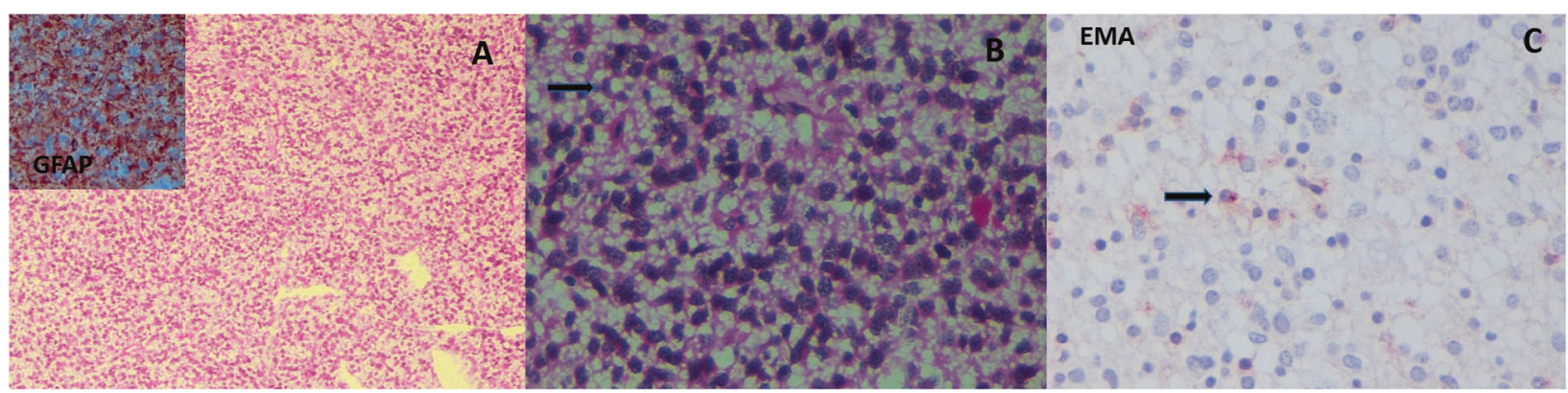

Fig. 2 Histopathological examination demonstrating features of a cellular ependymoma (WHO Grade II). Paraffin section of the lesion showing a cellular tumor with: a round to oval cells arranged in fibrillary matrix with strong and diffuse GFAP positivity (Inset),

reflexes in the upper and lower limbs. In view of a poor respiratory effort, she required intubation and mechanical ventilation. A whole-spine MRI (Fig. 3) showed a diffusely enlarged spinal cord with a holocord, heterogeneously enhancing intramedullary lesion extending from the conus up to $\mathrm{C} 3$ with edema extending cranially to the pontomedullary junction (Fig. 4). There was also evidence of the lesion within the lumbar canal with diffuse thickening of the cauda equina. The recurrent lesion was iso- to hypointense on T1 WI and predominantly hyperintense on T2 -WI with areas of mixed intensity. Brain MRI did not show evidence of intracranial disease. She was started on intravenous steroids and planned for decompression of the tumor. However, her respiratory status deteriorated rapidly, and she suffered a cardiorespiratory arrest soon after admission. She succumbed to her disease the following day. b high-power view of the same demonstrating attempted ependymal rosette formation (arrow), and c paranuclear dot positivity for EMA (arrow). [Hematoxylin and eosin: $\mathbf{a} \times 40 ; \mathbf{b} \times 400$ ] [Avidin Biotin Complex immunoperoxidase (A-inset) $\times 400 ; \mathbf{c} \times 400]$.

Tumor sample from the first surgery was not available for retrospective hormonal and genetic analysis, and the recurrent tumor could not be obtained for analysis as the relatives did not consent for an autopsy. Based on the radiological and clinical findings, a final diagnosis of an aggressive holocord recurrence of the conus ependymoma was made.

\section{Discussion}

The hormonal milieu of pregnancy is known to predispose to the occurrence of tumors across various organ systems with an incidence of around 1 in 1000-2000 pregnancies [11]. The commoner pregnancy-related tumors include breast, hematological, and dermatological malignancies 
Fig. 3 Thoracic spine MRI showing a diffusely enlarged spinal cord with a holocord intramedullary lesion. a T2weighted sequence demonstrating the lesion to be predominantly hyperintense with areas of mixed intensity in the conus. b Gadolinium enhanced T1-weighted sagittal image showing heterogeneous enhancement in the dorsal spine. c T2-weighted axial sequence at T10-11 level showing an enlarged cord.
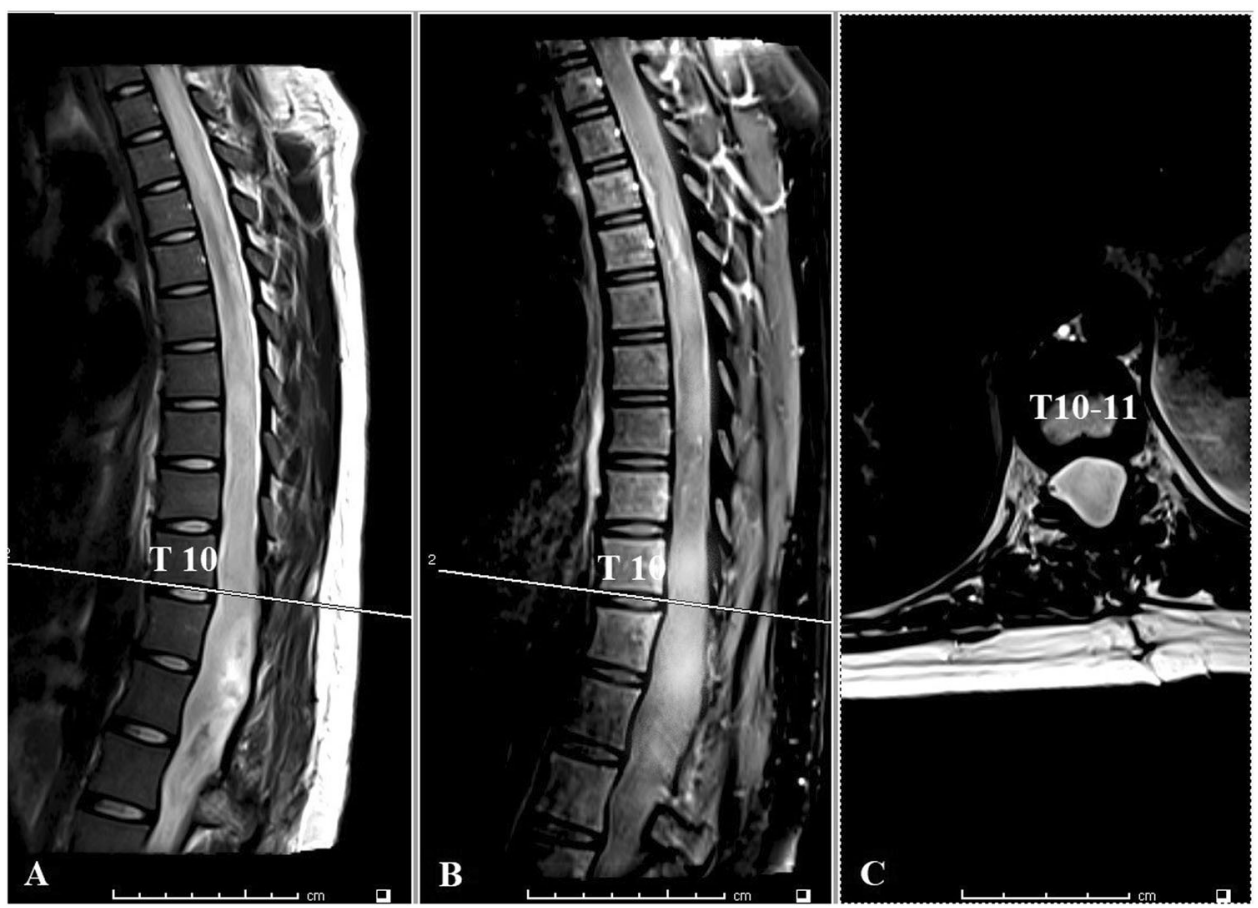

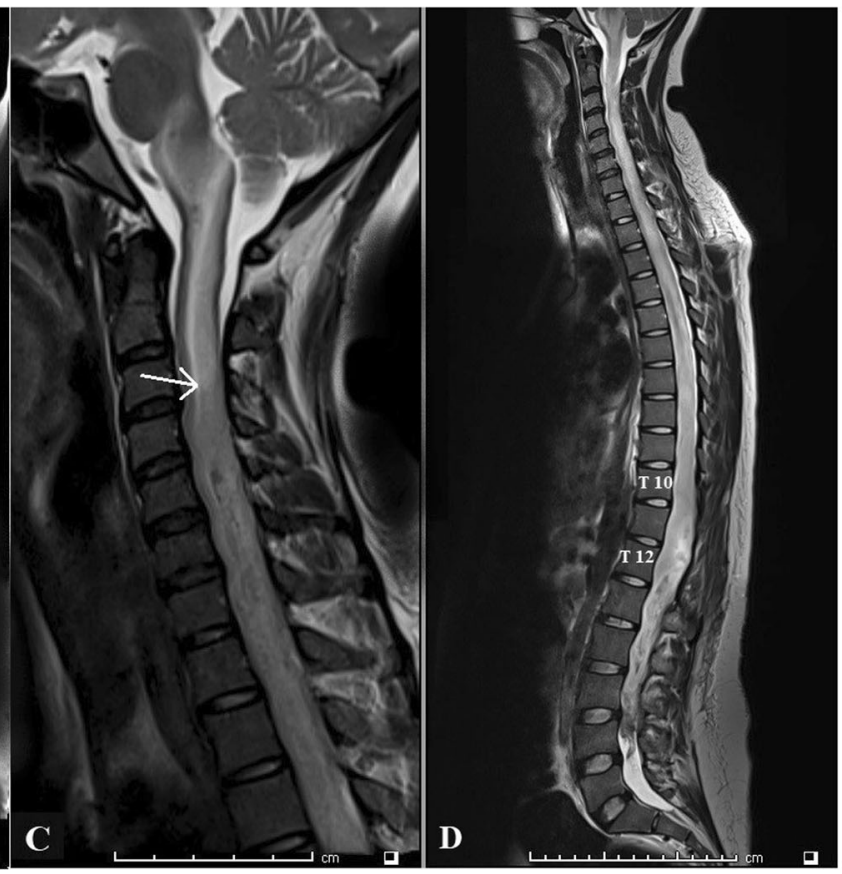

intramedullary lesion extending up to C3 (arrow) with edema extending cranially to the pontomedullary junction. d Sagittal T2weighted image of the whole spine showing a diffuse holocord involvement by the lesion. Diffuse thickening of the cauda equina is noted as well.

delivery [13]. Among all the PRSTs reported in literature, intramedullary ependymomas have been reported only eight times (Table 2) [4, 14-19].

Various mechanisms have been postulated to explain the growth of PRSTs and also the exacerbation of symptoms in 


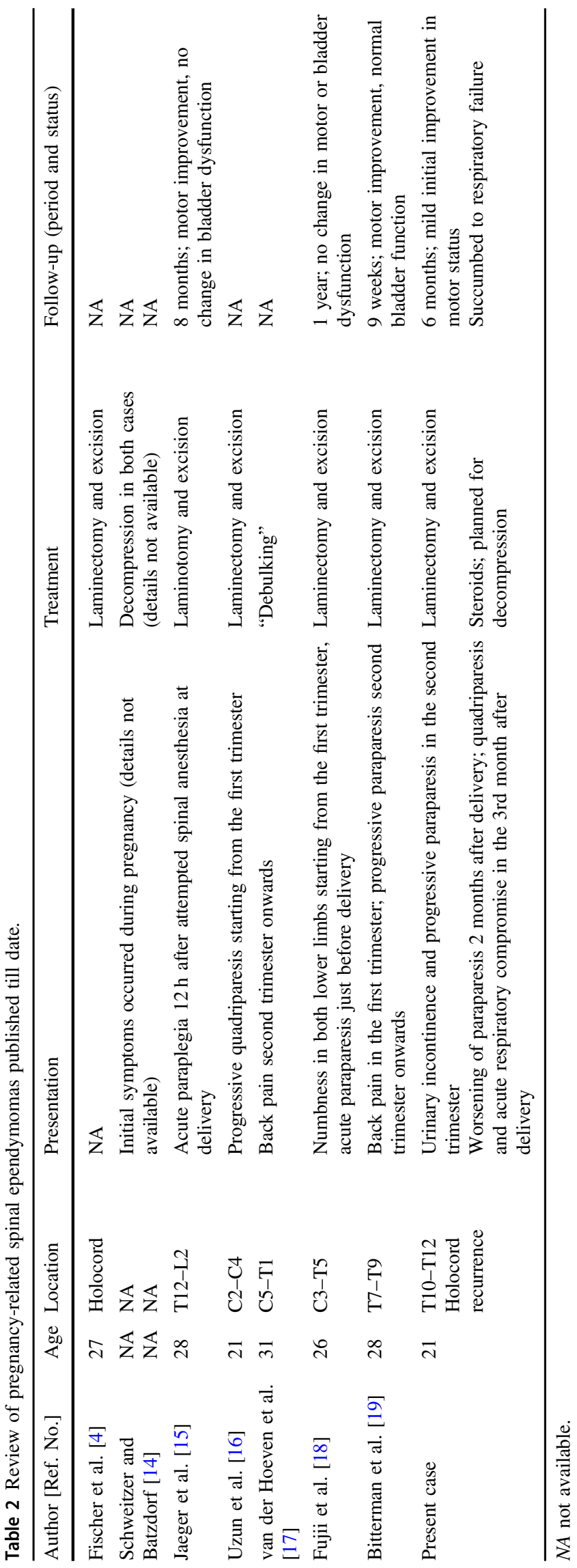

previously asymptomatic lesions [13, 20-24]. These include hormonal and hemodynamic changes, presence of estrogen receptors (ERs) and progesterone receptors (PRs) [25, 26] and increased levels of angiogenic and growth factors [27]. For example, neuro-epithelial tumors including ependymomas have been proven to express the receptors ER- $\beta$ [13] and PRs [28] either of which can modify tumor progression. In the case of vertebral hemangiomas, the mechanism of growth is thought to be multifactorial. Implicated factors include hormonal changes that increase venous distensibility, and hemodynamic changes that result in redistribution of blood volume through the vertebral venous plexus [22]. The latter hemodynamic mechanism also explains the nocturnal exacerbation of symptoms, with the supine position heightening uterine pressure on the vena cava and causing subsequent venous congestion and cord compromise [17].

Review of the previously reported pregnancy-related spinal ependymomas (Table 2) reveals that the clinical presentation and outcomes in all these cases were similar to those of regular spinal ependymomas. One patient presented with a holocord tumor after delivery [4] similar to our case. The tumor in the other patients was limited to three or four spinal segments. While five of these patients developed neurological deficits and underwent tumor resection during pregnancy, one of them was diagnosed to have a spinal lesion after a failed attempt at spinal anesthesia during delivery [15]. One patient was found to be harboring a spinal ependymoma on postpartum evaluation of longstanding nocturnal back pain [17]. There was no tumor recurrence in any of the patients with documented followup. Our case is unique in that the tumor presented with an aggressive and fatal holocord recurrence within 6 months of near-total resection. Although a definite pathological diagnosis of the recurrent tumor was not possible in our case, the radiological characteristics were consistent with those of a holocord recurrence.

Clinical outcomes of low-grade spinal ependymomas are generally favorable, and biological aggression and poor outcomes are generally limited to WHO Grade III ependymomas $[29,30]$. A hypothesis to explain the aggressiveness of the low-grade tumor in our case would be that the tumor had strong steroid-receptor positivity, and hence was highly sensitive to the pregnancy-induced hormonal changes. A study of various primary spinal cord tumors [31] demonstrated cytoplasmic-ER and -PR positivity in a majority of the ependymomas. Findings from other studies as well $[13,28]$ indicate a strong possibility that steroids can promote the onset, differentiation, and growth of spinal ependymomas.

While the above hypothesis sounds tenable, it can only explain tumor aggressiveness till the early postpartum period, beyond which hormonal levels normalize to their pregravid status [13]. This then draws forth a possibility of an 
underlying molecular alteration that could have contributed to the aggressive recurrence of the tumor. A likely candidate would be a focal MYCN amplification [32] reported to occur in a subgroup of spinal ependymomas including the lower grade ones. $M Y C N$-amplified tumors typically demonstrate increased aggressiveness, early metastases with craniospinal dissemination, rapid progression after relapse, resistance to treatment, and poor overall survival [32]. We could not establish a $M Y C N$ alteration or histological evidence of malignant progression in our case. However, the clinical features like spinal cord invasion at presentation, holocord progression, and a dismal survival despite a near-total resection of the primary tumor were pointers to the abovementioned genetic alteration.

This case highlights an unusually aggressive clinical course of a low-grade spinal tumor during pregnancy. Further research is warranted on exploring characteristics like steroid-receptor positivity and genetic alterations like the $M Y N C$ amplification in spinal ependymomas. This could be utilized in formulating targeted genetic [33-36] or hormonal therapies to alter the biological behavior of such tumors.

Acknowledgements The authors acknowledge the contribution of $\mathrm{Mr}$. Nagesh B. (BPT, MPT-Neuro, and Neurosurgical Rehabilitation, MIAP), Head of Department, Department of Physiotherapy, SSSIHMS, Bangalore, in providing postoperative physiotherapy and rehabilitative care for the patient.

\section{Compliance with ethical standards}

Conflict of interest The authors declare that they have no conflict of interest.

Publisher's note Springer Nature remains neutral with regard to jurisdictional claims in published maps and institutional affiliations.

\section{References}

1. Schittenhelm J, Ebner FH, Tatagiba M, Wolff M, Nägele T, Meyermann R, et al. Holocord pilocytic astrocytoma-case report and review of the literature. Clin Neurol Neurosurg. 2009;111: 203-7.

2. Epstein F, Epstein N. Surgical management of holocord intramedullary spinal cord astrocytomas in children. $\mathrm{J}$ Neurosurg. 1981;54:829-32.

3. Horrax G, Henderson DG. Encapsulated intramedullary tumor involving the whole spinal cord from medulla to conus: complete enucleation with recovery. Surg Gynecol Obstet. 1939;68:814-9.

4. Fischer G, Pierluca P, Sindou M, Pialat J. Pan-spinal ependymoma. Apropos of 2 cases with complete exeresis. Neurochirurgie. 1975;21:5-20.

5. Nakamura S, Yamada H, Tajima M, Yoshida J, Kobayashi T, Kagemaya N. Intramedullary tumor involving from brain stem to conus medullaris. Shoni No Noshinke. 1980;5:199-203.

6. Tanaka H, Shimizu H, Ishijima B, Nakamura Y. Myxopapillary ependymoma of the filum terminale with a holocord cyst: a case report. No Shinkei Geka. 1986;14:997-1003.
7. Gunes HF, Ozdemir N. Holocord ependymoma. Turk Neurosurg. 2012;22:250-3.

8. Aryan S, Ghosal N, Aziz ZA, Hegde AS, Dadlani R. Infantile holocord cellular ependymoma with communicating hydrocephalus: unusual presentation of a rare case. Brain Tumor Pathol. 2014;31:47-50.

9. Bhaisora KS, Sharma P, Srivastava AK, Mehrotra A, Das KK, Sardhara J, et al. Single staged complete length excision of the holocord ependymoma: team work. J Pediatr Neurosci. 2015;10:396-8.

10. Cushing H. The intracranial tumors of preadolescence. Am J Dis Child. 1927;33:551-84.

11. Pavlidis NA. Coexistence of pregnancy and malignancy. Oncologist. 2002;7:279-87.

12. Van Calsteren K, Heyns L, De Smet F, Van Eycken L, Gziri MM, Van Gemert W, et al. Cancer during pregnancy: an analysis of 215 patients emphasizing the obstetrical and the neonatal outcomes. J Clin Oncol. 2010;28:683-9.

13. Meng T, Yin H, Li Z, Li B, Zhou W, Wang J, et al. Therapeutic strategy and outcome of spine tumors in pregnancy: a report of 21 cases and literature review. Spine. 2015;40:E146-53.

14. Schweitzer JS, Batzdorf U. Ependymoma of the cauda equina region: diagnosis, treatment, and outcome in 15 patients. Neurosurgery. 1992;30:202-7.

15. Jaeger M, Rickels E, Schmidt A, Samii M, Blömer U. Lumbar ependymoma presenting with paraplegia following attempted spinal anaesthesia. Br J Anaesth. 2002;88:438-40.

16. Uzun Ş, Kara D, Akbay A. Anesthetic management of a pregnant woman with a cervical intramedullar ependymoma. Acta Med. 2014;45:86-8.

17. van der Hoeven ME, de Pont LM, Koppen H. Severe nightly thoracic pain presenting during pregnancy: a case report. Case Rep Neurol. 2018;10:135-9.

18. Fujii K, Orisaka M, Yamamoto M, Nishijima K, Yoshida Y. Primary intramedullary spinal cord tumour in pregnancy: a case report. Spinal Cord Ser Cases. 2018;4:1-5.

19. Bitterman J, Donovan J, Lam M. Diagnosis and rehabilitation of a pregnant woman with spinal cord disorder due to spinal cord tumor. Spinal Cord Ser Cases. 2019;5:1-4.

20. Ross AE, Bojescul JA, Kuklo TR. Giant cell tumor: a case report of recurrence during pregnancy. Spine. 2005;30:E332-5.

21. Kiroglu Y, Benek B, Yagci B, Cirak B, Tahta K. Spinal cord compression caused by vertebral hemangioma being symptomatic during pregnancy. Surg Neurol. 2009;71:487-92.

22. Hayden MG, Gephart R, Kalanithi P, Chou D. Von Hippel-Lindau disease in pregnancy: a brief review. J Clin Neurosci. 2009;16:611-3.

23. Terra Júnior JA, Daneze ER, Terra GA, Etchebehere RM, Barbosa $\mathrm{AB}$, Terra SA. Subcostal schwannoma in pregnancy. Arq Neuropsiquiatr. 2012;70:901-2.

24. Roelvink NC, Kamphorst W, van Alphen HA, Rao BR. Pregnancy-related primary brain and spinal tumors. Arch Neurol. 1987;44:209-15.

25. Malawer M, Bray M, Kass M. Fluorescent histochemical demonstration of estrogen and progesterone binding in giant cell tumors of bone: preliminary observations. J Surg Oncol. 1984;25:148-52.

26. Olivera P, Perez E, Ortega A, Terual R, Gomes C, Moreno LF, et al. Estrogen receptor expression in giant cell tumors of the bone. Hum Pathol. 2002;33:165-9.

27. Yust-Katz S, de Groot JF, Liu D, Wu J, Yuan Y, Anderson MD, et al. Pregnancy and glial brain tumors. Neuro Oncol. 2014;16: 1289-94.

28. Liu M, Zhang K, Zhao Y, Guo Q, Guo D, Zhang J. Evidence for involvement of steroid receptors and coactivators in neuroepithelial and meningothelial tumors. Tumour Biol. 2015;36:3251-61. 
29. Khalid SI, Adogwa O, Kelly R, Metha A, Bagley C, Cheng J, et al. Adult spinal ependymomas: an epidemiologic study. World Neurosurg. 2018;111:e53-61.

30. Ostrom QT, Gittleman H, Truitt G, Boscia A, Kruchko C, Barnholtz-Sloan JS. CBTRUS statistical report: primary brain and other central nervous system tumors diagnosed in the United States in 2011-2015. Neuro Oncol. 2018;20:iv1-86.

31. Concolino G, Liccardo G, Conti C, Panfili C, Giuffre R. Hormones and tumours in central nervous system (CNS): steroid receptors in primary spinal cord tumours. Neurological Res. 1984;6:121-6.

32. Ghasemi DR, Sill M, Okonechnikov K, Korshunov A, Yip S, Schutz PW, et al. MYCN amplification drives an aggressive form of spinal ependymoma. Acta Neuropathol. 2019;138:1075-89.
33. Barone G, Anderson J, Pearson AD, Petrie K, Chesler L. New strategies in neuroblastoma: therapeutic targeting of MYCN and ALK. Clin Cancer Res. 2013;19:5814-21.

34. Colicchia V, Petroni M, Guarguaglini G, Sardina F, Sahún-Roncero M, Carbonari M, et al. PARP inhibitors enhance replication stress and cause mitotic catastrophe in MYCN dependent neuroblastoma. Oncogene. 2017;36:4682-91.

35. Gustafson WC, Meyerowitz JG, Nekritz EA, Chen J, Benes C, Charron E, et al. Drugging MYCN through an allosteric transition in Aurora kinase A. Cancer Cell. 2014;26:414-27.

36. Henssen A, Althoff K, Odersky A, Beckers A, Koche R, Speleman F, et al. Targeting MYCN-driven transcription by BETbromodomain inhibition. Clin Cancer Res. 2016;22:2470-81. 